\title{
Evolution: Much More than Genetics. The Need for a Holistic View
}

\author{
Jaume Terradas ${ }^{1}$ and Josep Peñuelas*,2
}

\author{
${ }^{I}$ Departament de Biologia Vegetal, Animal i Ecologia, i CREAF (Center for Ecological Research and Forestry \\ Applications), Universitat Autònoma de Barcelona, 08193 Bellaterra, Spain \\ ${ }^{2}$ CSIC-CEAB-CREAF Ecophysiology and Global Change Unit, CREAF (Center for Ecological Research and Forestry \\ Applications), Universitat Autònoma de Barcelona, 08193 Bellaterra, Spain
}

\begin{abstract}
Since Darwin's time we have known that natural selection, acting upon variations, is the key to understanding biological evolution. After passing through the filter of natural selection, these changes generate new life-forms. Such lines of thought are still widely advocated today in science, but many non-scientists continue to accept creationism, Lamarckism and other ideas not supported by evidence. Even though many books and papers are published yearly to explain Darwinian evolution, and many documentary films are shown on TV, resistance to Darwinian evolution does not decrease. In fact, it is on the increase, not only in the USA but recently also in Europe. Perhaps those of us who write and lecture on Darwinian evolution are doing something wrong. For example, many books on the subject emphasize genetic mechanisms, although it is obvious that the evolution of the genome alone cannot suffice to explain the evolution of life on Earth in all its manifestations. In this paper we present an all-embracing vision of the evolution of life -- a coevolutionary process that is not strictly biological but also environmental, social and cultural, and which takes into account the important role played by incorporations and interactions in networks. We believe that it is only by emphasizing the continuity between matter on the one hand and biological, social and cultural evolution on the other that the gap between micro- and macro-evolution can be filled in an understandable way for non-scientists in need of a comprehensive view.
\end{abstract}

\section{MORE THAN GENETICS: EVOLUTIONARY IN- CORPORATIONS, DISTURBANCES AND CONNEC- TIONS}

The current attack of creationists against Darwinian evolution is known as "Intelligent Design", often called "Intelligent Design Theory" as if it were on the same footing [1]. Even educated people, 150 years after the publication of The Origin of Species, still do not understand that evolution is solidly established and that there is no scientific basis to Intelligent Design. Possibly understanding has been blocked by the failure of experts to explain that evolution is more than the sum total of small mutations and selection. Thus neoDarwinism has obscured the clarity of Darwin's theory by emphasizing just the genetic mechanisms of innovation, like mutation and other small changes. Evolution of life on Earth is not only the result of genetic change but also of biological and physical incorporations and of ecological, social and cultural network connections, all duly filtered by selection along historic, contingent processes [2-4].

This enlarged view of evolution, with more emphasis on incorporation processes and environmental and biotic contexts, was promoted in the summer of 2008 , at a meeting in Altenberg, Austria, on the future course of evolution. The organizer, Massimo Pigliucci, expressed the hope of "moving from a gene-centric view of causality in evolution to a pluralist, multi-level causality". Nevertheless many scientists

*Address correspondence to this author at the CSIC-CEAB-CREAF Ecophysiology and Global Change Unit, CREAF (Center for Ecological Research and Forestry Applications), Universitat Autònoma de Barcelona, 08193 Bellaterra, Spain; E-mail: josep.penuelas@uab.cat do not agree, although the enlarged view would make evolution easier to understand and accept. Many changes have occurred that are not merely genetic. Any biologist or geologist knows this, but most have preferred to emphasize just the basic mechanisms.

The fundamental problem in communicating the cogency of Darwinian evolution, however, is not on the level of competing theories. Evolution is a theory in the scientific sense of that term; Intelligent Design is a cosmology, a way to understand the Universe and the humanity's place in it in totality, and therein lies its appeal. Most people want to have a global view of how the universe and life came to be. They want to know how everything fits together, and so Intelligent Design appeals because it gives them a tidy package - which science does not. The challenge, then, is to provide a far more comprehensive view of evolution while remaining within the methodological bounds of science.

From Darwin we know that natural selection acting upon variations is the key to understanding biological evolution. There is no evolution without innovation steps. NeoDarwinism places great emphasis on innovation through random changes in the genome, caused by processes such as mutation, translocation and inversion, hybridisation and genetic drift. These changes, after passing through the filter of natural selection, generate new life-forms. Such lines of thought are still vividly alive today, although it is obvious that the evolution of the genome alone cannot suffice to explain the evolution of life on Earth, an evolution that is dependent on far more processes than mere genetics ("descent with modification"). We need an all-embracing, yet still Darwinian, vision of the evolution of life; a co-evolutionary 
approach that is not strictly biological but also environmental, social and cultural, with a more explicit recognition of the important role played by incorporations and interactions in networks.

Certainly, the sense of the term "evolution" as a historical change is different from Darwinian evolution by natural selection, which is applied to biological evolution. and which is just a specific case of historical change. Evolution on Earth is not just a matter of genetic change, but is also a matter of changes in the environment and physicochemical structures, and, in many cases, it depends on the relationships between different organisms. Constructive and destructive processes also exist in the evolution of societies, technology and other complex systems. The Roman Empire historian Mommsen said that the history of any nation is "a large system of incorporation". For the Spanish philosopher Ortega y Gasset, any historical process of increasing complexity implicates incorporations, and not merely processes of expansion from an initial nucleus. Biological incorporation has also played a role in the evolution of life (e.g. the eukaryotic cell includes organelles that previously survived as autonomous microorganisms) and life organization ecosystems and ecological interactions between species are the result of a continuous tale of incorporations and local extinctions. Incorporations can be definitive or maintain some degree of fluctuation, or indeed, conflict. The persistence of new systems formed by aggregation or incorporation has to pass through external selective filters, as Darwin has already established. However, it is of note that in biological evolution, while complexity generally increases by slow steps, from time to time there are very abrupt or catastrophic events, involving disturbance or even destruction. Incorporations, disturbances and other processes aid to provide a large framework for evolutionary processes.

\section{FROM ATOMS TO EUKARYOTIC CELLS, PLANTS AND ANIMALS}

It is clear from the study of the evolution of atoms, galaxies or the Solar System that many changes in the evolution of matter took place also as a result of historical processes of evolution, construction and destruction, and that these processes include aggregation, incorporation, division and/or fragmentation. Present ideas on the origins of life do not look for a primordial organism, but for a kind of pre-biotic chemical ecosystem, inside partially closed environments [5, 6]. In these environments complicated molecules evolved from chains of atoms or from simpler molecules and became linked in hyper-cycles of reactions [7, 8], where genetic material flowed easily. Hence these evolutionary processes also worked by incorporation and fragmentation. Even today, prokaryotes exchange genetic material between species in a more promiscuous way than in the sexual reproduction of eukaryotes. Their genomic exchanges include incorporation of alien genes or clusters of genes coming from distantly related taxa, without a homologue in the recipient strain [9].

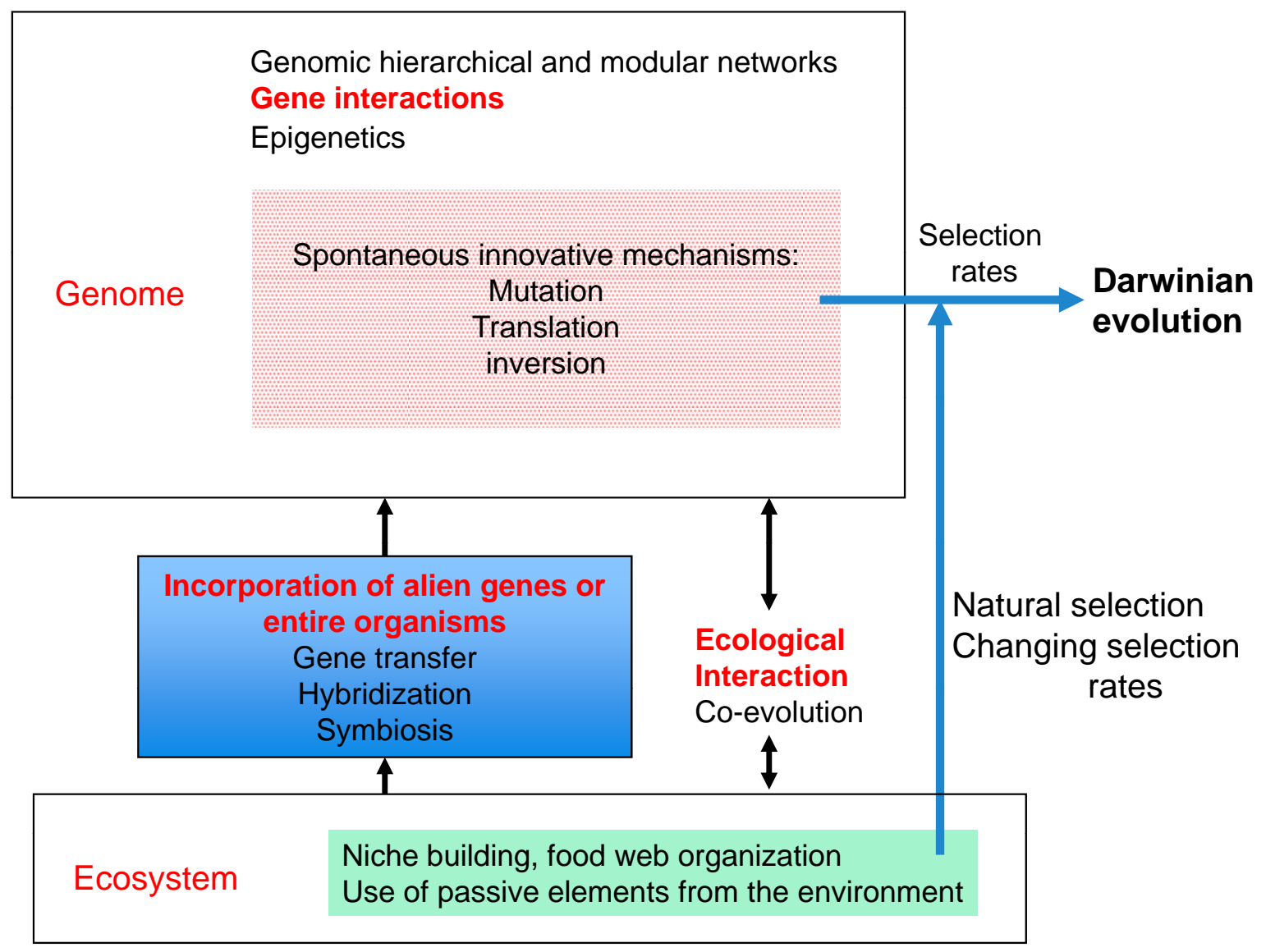

Fig. (1). Spontaneous changes in genome, like mutation, explain only a part of the innovation process, a basic genetic mechanism. The incorporation of alien genes or entire organisms modifies the genome and the ability of the organism to perform functions. The interaction within the ecosystem modifies rates of selection. The entire process is filtered by Darwinian selection. 
In addition, bacteria and viruses can also transfer genes from one organism to another, including eukaryotes [10] (Fig. 1).

The endosymbiotic theory [11] provides a view of eukaryote organisms similar to Russian dolls. The origin of mitochondria and plastids as independent prokaryotic cells is now largely accepted. Some algae have been formed by up to four successive symbiotic processes, a smaller organism becoming integrated into a larger one at each step. Significant evolutionary incorporations can also occur outside the cell, at an organism level $[12,13]$.

As we said before, Neo-Darwinism emphasizes small changes: mutations (favourable, noxious or neutral), and recombinations or translocations of DNA fragments. There is no need for large changes to generate new species, and to a considerable extent evolution certainly occurs in the neoDarwinian way. But this is not the entire story. In the evolution of life on Earth, there are larger, sudden changes, as, for instance, very fast extinction processes due to meteorite impacts, connections between previously isolated habitats and so on. Also, any evolution is co-evolution: all the organisms evolve with respect to other organisms and, to some degree, they co-evolve with the physicochemical environment as well. This is well-known, but must never be overlooked, because it means that random genomic changes occur in evolutionary processes due, sometimes, to very dynamic changes in the abiotic and/or biotic environment.

The old idea of "one gene-one protein" has now been discredited. Genomes are not homogeneous linear sequences, but hierarchical, modular systems [14, 15]. Biological function is determined in these entire networks of genes, proteins and other factors linked by non-linear feedback loops. Some authors, like Jablonka and Lamb [16] (2005), have argued that epigenetic changes, such as a minor chemical addition, e.g. a methyl group in a DNA base, not only can turn off a gene but can also be passed on to the next generation. This implies that a diet change during gestation could influence in some way subsequent generations. However, this interpretation remains controversial.

Evolutionary changes also proceed depending on body plan. Genes shape the body, but they are expressed in the context of the development, meaning that a dynamic environment also directly shapes gene expression through feedback processes. In addition, links between tissues during development can channel phenotypic changes, meaning that gene mutations are not necessarily expressed in each tissue. Even a small mutation may have produced rapid, substantial phenotypic changes along the evolutionary process, due to the hierarchical links between anatomical structures. Body plans are emerging properties. Furthermore there is functional redundancy. There is not a unique regulatory pathway to achieve one function, but several, and if one is changed, the others ensure that the system keeps functioning. For that reason, hidden changes in networks can produce new solutions when faced with future challenges. The resilience due to the redundancy in regulatory pathways opens the way to faster evolution in gene regulatory networks, as compared to protein-coding genes.

Some fragments of the genome coding for proteins, sometimes involved in groups of reactions, have remained constant in most organisms along many millions of years.
Some gene ensembles are true toolboxes that can be used to do different things in different contexts. The hierarchical, modular organization means that sudden incorporations of entire modules (even entire cells) can occur, as well as sudden hierarchical reorganizations.

Symbiosis has produced extremely important evolutionary jumps, such as the leap from prokaryotes to eukaryotes and the acquisition of functional packs, in particular the capacity for aerobic respiration (mitochondria) or photosynthesis (chloroplasts) [11]. The acquisition of a microbe's physiological capacity can confer substantial fitness benefits to hosts [17]. It is a way of organization or incorporation which has some analogy to the process that Mommsen described for building Empires. In plants, it is possible to observe, quite frequently, how at least a part of the genome of a hosted organism is integrated in the genome of the host [18].

The vast majority of vascular plants depend on fungal mycelia in the mycorrhizae, in order to extract soil resources, and some of them on $\mathrm{N}$-fixing bacteria. It is interesting to observe that the plant genome machinery which regulates mycorrhizae formation is the same that has been used later to control the formation of bacteria nodules. This is an example of a toolbox used for a different aim that reminds François Jacob's famous description of life as a tinkerer. The fungi or bacteria send chemical messages (aminoacids) that activate certain specific plant genes, whose response permits the development of mycorrhizae or nodules. The finding that the formation of mycorrhizae and nodules is regulated by proteins produced in the chloroplasts of the host plant [19] is fascinating, because it means that the admission of new root symbionts depends on another older endosymbiont. Some symbioses involve three-species interactions. For instances, a beetle, Dendroctonus frontalis, uses an antibiotic (mycangimycin) made by an actinomycet bacterium to protect its fungal food source, Entomocorticium sp., from a competitor fungus, Ophiostoma minus [20].

Digestion in multicellular animals is made by large by their intestinal flora of microbes. Without them, probably multicellular animals would have never existed. The chemical abilities for digesting food were acquired all at once by incorporating these pre-existing prokaryotes, and not by mutations in the animal's own genome. Nevertheless, some genomic changes have also occurred after the incorporation as a result of co-evolution, both in animals and microbes, finetuning the reciprocal relationships. Insects have intimate associations with bacteria: they even possess internal organs (bacteriomes) or anatomical features on their exoskeleton which provide these bacteria an appropriate environment to grow in. So, bacteria not only aid insects to digest food but also some are producers of chemicals that can protect them against fungi and other pathogens [21]. In this way, evolution creates complex, mixed organisms, with new abilities. Examples are everywhere. Similar developments occur in processes that are not triggered by incorporations, but instead, are activated by the simple connection between elements that were previously unrelated, as we will see later.

\section{MICRO- AND MACRO-EVOLUTION}

Microevolution, namely events of change at or below the species level, is quite easy to prove. An overwhelming amount of examples are available from genetics. Specific 
variability is largely accepted, whereas it is sometimes more difficult to explain macroevolution. Questions arise such as: Why fossils belonging to different phyla start to be observed in rocks of certain age, but not older? or Why does evolution promote small changes that, by themselves, apparently do not confer any advantage at all but, in the long run and following a clear trend, will build an organ with an adaptive function, like a wing or an eye. The problem in accepting evolution is much more related to macroevolution (an obvious answer to this dilemma is that microevolution accumulates and become macroevolution when long time periods are considered. However, this is not convincing, not only for creationists but even for at least some biologists [22]. An enormous amount of literature exists on this subject. Creationists have made a large effort to emphasize the difficulties of explaining macroevolution through the web and in many books, because they consider it as a crucial point. The lack of transient forms between phyla can be explained by the unavoidable discontinuity of fossil records, but while microevolution can be directly observed in the lab or the field, macroevolution poses more problems because big changes in morphology or body plans take much more time than available in experiments. This fact favours many speculations.

We agree with the Neo-Darwinian view that the discussion on gradualism and punctuationism in this context is not really relevant. We consider that the difference between gradual or punctuational patterns is only a matter of time, and it is quite obvious that evolutionary rates are not constant in space or time. We believe that there are no other mechanisms needed than those we have mentioned. It is true that there is no new, definitive argument to reduce mac- roevolution to microevolution. Nevertheless, we think that a Darwinian explanation of macroevolution appears much more convincing if it encompasses an enlarged view that includes the role of incorporations, co-evolution and intense, rapid changes in selective pressures, in addition to a merely genetic view. Jablonski [23] (2008) and Reznick and Ricklefs [24] (2009) support the idea that understanding macroevolution requires the integration of ecology, evolution and the role of history in shaping the diversification or decline of lineages. The latter authors also recall the earlier Darwinian proposal of divergence and extinction being the essential mechanisms in the bridge between microevolution and macroevolution.

Any vision of the evolution of the complexity of life on Earth must accept that the evolutionary process is the result of genetic change, and that genetic change can be accelerated with changes in selective pressures proceeding from the physico-chemical or biotic environment. But it must also be recognised that genetic and functional change can be the result of incorporations and the interactions inside dynamic ecological, social and cultural networks. This means that evolution is not simply the product of random self-generated modifications followed by selective processes. With this statement, we do not intend to refute in any way the NeoDarwinian explanation, but to include it in a more comprehensive view. The novel idea here is that evolution will be more easily understood if we are able to enlarge the focus in order to include many processes that contribute to accelerate its rate. Certainly, co-evolution involves genomic changes, but it would not proceed so fast without rapidly changing

\section{INCORPORATION}

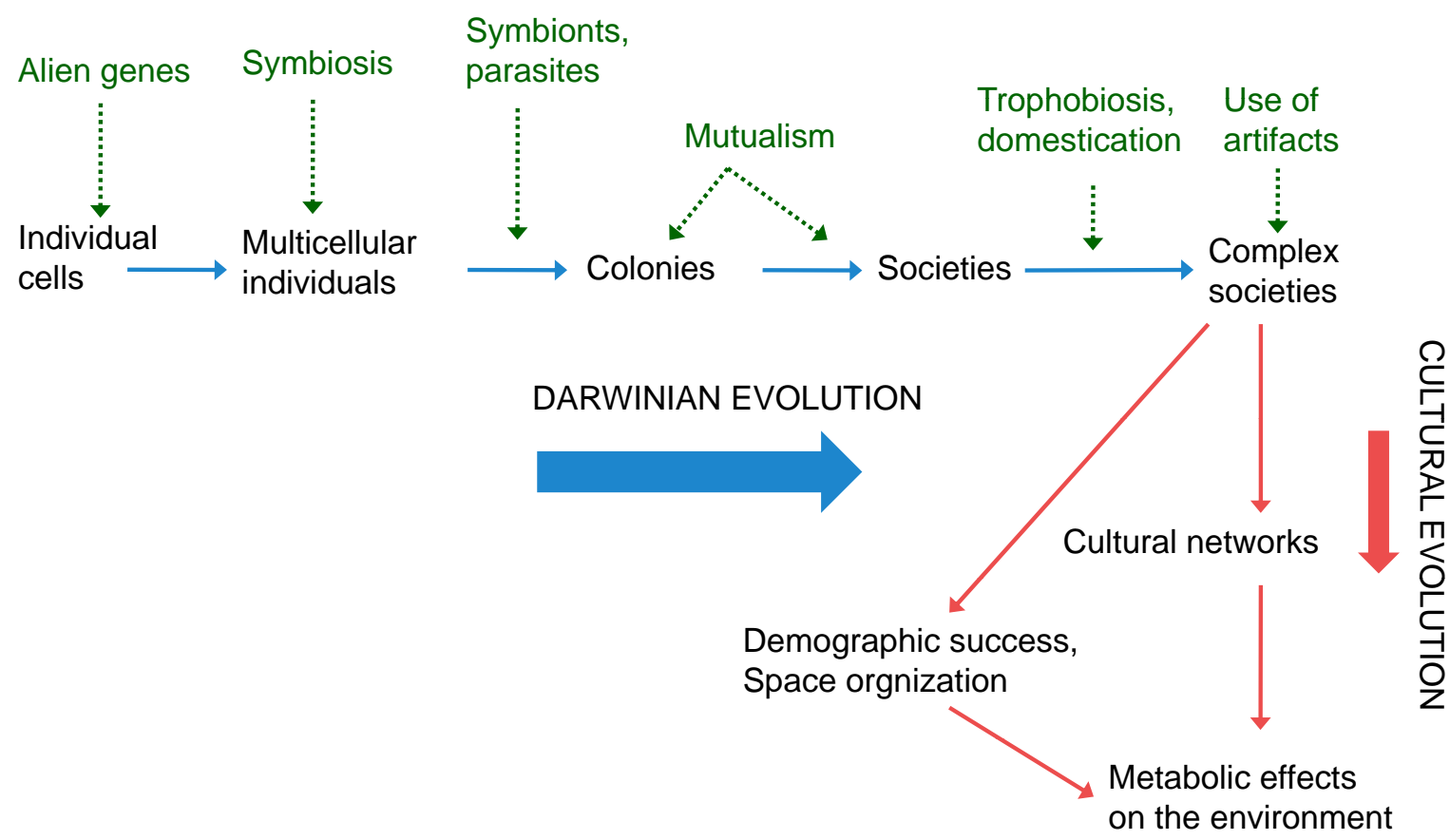

Fig. (2). Evolution from individual cells to multicellular organisms, to colonies, to societies, and to complex societies involves incorporation at any stage, as well as selective processes. In complex societies (ants, man) other species are incorporated by trophobiosis or domestication. Use of artifacts and other species is much more increased by cultural processes that do not necessarily obey Darwinian selection. 
selective pressures induced by the interaction network, and without the multiple processes incorporating pre-existing packages of abilities to use resources. Selection can act at different levels, pairs of species (co-evolution), kin or group, and it has been shown that co-evolution increases mutation rates, imposing selection for evolvability [25].

\section{ECOSYSTEMIC RELATIONSHIPS}

Life evolves also at an ecological level, by constantly building niches [26], food webs and ecosystems. In the biological literature, prey-predator relationships attracted more interest in the past than mutualistic interactions, even though Darwin himself did a lot of work on pollination and other associations involving exchanges of services between species. Now, this trend is changing, and mutualistic webs are becoming a prominent field of study. In fact, we can find in nature a whole array of possibilities, from symbiotic fusion of two species into one, to non-internalized symbiosis, opportunistic symbiosis, trophobiosis, domestication in the case of human societies with plants and animals, slavery, parasitism, mimics and other delusory relationships, species that behave as robbers, competition and predation. Genetic changes are selected in this context; this is co-evolution. When the evolution and speciation of a plant genus is associated with the parallel evolution of pollinator insects, there is an acceleration of evolutionary processes. Speciation in both groups occurs repeatedly over a relatively short period of time, because plants co-evolve with insects. This game, that cannot be limited to pairs of species, occurs within the extreme complexity of ecological systems. The building of such a web of links can be described as an incorporation or assembling process. Results are complex networks [27] (Fig. 2).

Many animals use non-living elements in their surroundings in the search for food, or to build shelters or defence structures, such as nests or burrows. For instance beavers drag branches to dam rivers and to build lodges, birds use twigs to make nests, sea otters use stones to crack open crab shells and birds and great apes use, and some even modify, branches to get food. Any organism that employs an external resource - be it a piece of DNA, another organism, or a passive element acquired from its surroundings - is unleashing a multi-faceted process of evolutionary acceleration, even if some changes affect directly the genome and others, like those due to cultural processes, force the genome to adapt to them. Viz.(1) the organism will be more successful and its populations will multiply; (2) by increasing its ability to alter its environment, selective pressures change and evolutionary changes occur more rapidly; and (3) innovation generates above all in man - many new possibilities for further innovation, and positive feedback soon accelerates technological evolution [28].

Like in any complex system, in an ecosystem there are different scales of organizations, with causal relations proceeding bottom-up, from smaller to larger scales, and constrictions proceeding top-down. Ecological webs are similar to other hierarchical multi-scaled webs, like genomic or social webs, and there has been much interest in understanding the role of variables like connectivity or diversity [29], or the way in which complex organizations tend to approach to the edge of chaos [30, 31]. The latter is a state where network elements are not so tightly linked as to provoke a freezing of the system, nor so loose as to make its persistence impossible. Webs are the result of an incorporation process, each organism acts on the environment, and the environment selectively filters the next generation. We can perhaps speak of a double, genetic and ecological, heredity, with a coevolutionary coupling between selection and construction, between resource use and evolution of use efficiency. Many years ago, Margalef [32] (1959) already mentioned the adherence between evolution and succession.

Practical aspects, for instance in conservation biology, drive us to new theoretical considerations. What happens when two complex systems suddenly contact each other? Usually, the relations are asymmetric and the Saint Matthew principle rules the process: the more complex and organized system takes advantage of the link and drains resources from the less organized one. The more organized system increases its own organization, whereas the simpler one loses elements and internal links, and the energy flow through it accelerates. This is true for two species, two trophic levels, two ecosystems or two societies. The effects are an increase of the organizational degree in one pole and a decrease in the other. In the integration of mitochondria or chloroplasts into a eukaryotic cell, these entities are now considered organelles and have lost selfhood and a large part of their genomes has been added to the cell nucleus. If herbivorous herds are introduced into a field, woody plants, with a more complex structure, are lost, and we have a vegetation of grasses with a fast turnover and a simpler structure, but the system becomes more complex by the addition of herbivores. If humans exploit an ecosystem, they favour short living species, with earlier sexual maturity, but a cultural network adds complexity. Military or economic imperialism usually enriches the metropolis and destroys the cultural and social organization of the colony. These similarities could well be the result of common properties of complex systems

\section{HUMAN EVOLUTION}

Biology places man and the human mind in the context of life in evolution. Humans are part of Nature and have evolved within Nature. Darwinian revolution is completed by ecological revolution: humans are natural beings, but also an element within ecosystems. Humans evolved, like the other species, through a historical process, affected by random and an active natural selection. Our genome is very similar to that of other primates, and parts of it are common with other organisms, many with mammals, but still some with yeasts. Nevertheless these changes were not merely products of our genome. We know that at the origin of differentiation between hominids and chimps, a climate change promoted the growth of savannah vegetation over large areas of Africa, an example of contingency in evolutionary processes [33]. This large environmental change "pushed" (by a change in selective pressures) hominization. There is also genetic evidence (a very high genetic homogeneity) of a population bottle-neck in our history. All of us descend from a small population of some hundreds or a few thousand people living in Africa [34]. Our unusual mental capabilities have been built in a modular way, and our conflicts between emotions and reason are a consequence of evolutionary tinkering: on a pre-existing brain. A predominantly new section 
was developed rapidly (just millennia) that permits abstract and symbolic thinking, but the old brain did not disappear.

At the same time, many of our bodily functions are in fact, like in other multi-cellular organisms, consequences of the abilities of the ecosystem that we carry with us, primarily in our guts and mouth, and are therefore a consequence of incorporation. Superior organisms are not individuals, but complex systems including one host organism and millions of smaller organisms that do a large part of the work. We are their environment, and they can have various relations with us. They can be parasites, symbionts, or any of the array of intermediate possibilities. Sometimes they can fluctuate from one to another type of association. Benign, kind collaborators can become cruel enemies feeding on our tissues when a wound permits them to reach an unusual zone of our body. This is reminiscent of Mommsen again.

\section{SOCIAL AND CULTURAL EVOLUTION}

Many species form colonies and some are social, for instance most ants and termites. Societies are the result of mutualistic integration of individuals in an increasingly complex organization. There is collaboration, division of labour and communication. The principal target of natural selection in the social evolution of insects is the colony, whereas the unit of selection is the gene [35]. Selection is a multi-level process $[36,37]$.

The evolution of sociability has appeared in different phyla. Sociability requires, certainly, a genetic trend to cooperate, but the result is a radical change in the actions and reactions of the species and its environment. The advantages of reciprocal altruism and kin selection have been recognized in many species, but in the case of humans some authors have proposed the existence of a strong altruism: an individual can sacrifice himself in the benefit of other unrelated individuals, with no genetic advantage [38]. There are many possible interpretations, based on ideas like the role of prestige in human societies or the possibility that emotional responses in hominids evolved inside small groups of huntercollectors with a high percentage of kin (then, heroic altruism could be an evolutionary remnant of kin selection that has lost its sense in modern societies).

Ecosystems assimilate species by migration or innovation. Ants and human societies incorporate species by trophobiosis or domestication. The transition to grazing and agriculture in humans was probably a consequence of a climate change and/or a reduction in the availability of prey. Initially the population suffered an impoverishment in diet, and harder work was needed to get food than in the prior times of hunting and collection. Domestication is a selection process that, in its beginnings, did not have precise aims, due to a lack of models [39]. It consisted simply in retaining individual animals that were kinder towards humans. With them, human societies became mixed societies [4], some animals living in close contact with humans, even in the same rooms, receiving individual names and exchanging their microbes with people. This, at first, impaired the health of human populations, and was of great importance later, when these populations became resistant to certain diseases and entered in contact with other populations who were not, provoking higher mortality rates that were more effective in destroying entire civilizations than war itself [40]. Mixed societies are a new evolutionary phase that appeared as a result of incorporation processes. Also, domestication enlarges the range of phenotypic variation in the species compared with their wild ancestors, a factor that can increase evolutionary rates.

Some species are engineers. They transform their environment to take more advantage of its resources. This is the case for trees and fungi, eusocial insects, corals, stromatolites, beavers and hominids. Roots and branches drive nutrients and water to the leaves, gaining control of space, especially with the evolutionary invention of wood. Humans have greatly developed the control and transfer of external resources thanks to their mind and social abilities. In mixed societies, domestic animals have contributed to transport, allowing the organization of markets with an area of influence reaching distances of 30 or $40 \mathrm{~km}$ available once or twice a week [41], and facilitating long journeys. With wind and animal energies, entire ecosystems (mixed societies, with all the associated species like microbes, weeds and so on) have travelled between continents. The evolution of mixed societies, now composed by men, associated species and machines, continues. A number of our domestic animals are slaves under cruel exploitation, others are wandering pariahs, another group are spoilt pets.

Yet human and animal biological energy was much less powerful than fossil fuels. Their use was a new step in social evolution occurring over the last 150 years. If agriculture deeply changed landscapes, in the industrial era the rate of transformation of landscape structure and metabolism multiplied. This is now provoking significant and severe changes in the air and oceans. Selection pressures are changing, and evolution will surely be induced in many species as a result.

Culture and technology has also evolved through innovation and incorporation. Robotics is producing new active elements in society. There are artefacts taking care of the ill or used as prosthesis. Biological evolution in humans and domesticated animals is now completed culturally with nonbiological (and in the future, perhaps also biological) elements that permit the recovery of lost abilities or the development of new ones. We are becoming more and more cyber-humans, and robots have been added to plants and animals in our mixed societies. These changes can provoke small fine- tuning changes in genomes. All this follows the same logic, humans learn to use, to their own benefit, any resource or material found in their environment or in their own body. Selective pressures can be changed and evolution is promoted. Genetic engineering must be understood in the same context. Humans can increasingly manipulate genes, for example to reduce disease risks or to increase abilities.

Evolution of cultural behaviour has needed genetic changes as well. Examples are the gene FOXP2, involved in human speech, most probably genes ASPM and MCPH1, related with brain size, and gene DUF1220, that encodes a protein which is active in the brain and has many more copies in humans than in any other species, the region HAR1 that encodes for a small RNA that has evolved faster than any other, and a large array of duplications, deletions and other rearrangements, some causing diseases specific to humans but which are perhaps expanding genetic diversity [42]. Cultural evolution certainly escapes from natural selection in the sense that technological evolution is not ruled by 
a mere selective mechanism; the economical and political power of a corporation can maintain a product in the market, avoiding that a better one succeeds. In fact, prosthesis, bioengineering or genetic engineering, like most aspects of medicine, try to elude the effects of selection, and so it is for millennia clothing, tools or agriculture. But this probably increases genetic variety in humans and makes the persistence of many mutations possible that would otherwise have been eliminated by selection. Thus, culture is modifying genes. Some authors [43] think that culture has contributed, with exposure to very diverse climates through human expansion, to a very rapid evolution of humans during the last ten thousand years. The best known example is cattle domestication associated in independent populations to genetic mutations allowing adults to digest lactose. Culture and genes are interacting, but in general, it is more advantageous to increase learning abilities than to fix specific capacities in the genome.

Even so, in a very general sense, cultural evolution follows the same logic as engineer species: to use materials and energy from the milieu, and to organize space in order to increase the control of the environment, and thereby, to increase the population size. Cultural evolution also depends on the natural selection of genome to begin its development, and culture continues interacting with the genome all the time. Culture is a new complex system anchored on other complex systems: genome, proteome and ecological networks.

\section{CONCLUSION}

We conclude that the evolution of the complexity of life on Earth is the result of genetic change, but also of biological and physical incorporations and of interactions in dynamic ecological, social and cultural networks that stimulate, through new selective pressures, elevated rate of genetic change. It is therefore not simply the product of random selfgenerated modifications and consequent selective processes since many more events have occurred, even if genetic change is the basic mechanism. It is only from this perspective that the gap between micro- and macro-evolution can be filled. This makes evolution more easily understandable to non-scientists looking for a cosmology as a way to understand the Universe and the humanity's place in it in totality, by emphasizing the continuity that exists between matter, biological, social and cultural evolution. We hope that this view can also become a guideline for future research.

\section{ACKNOWLEDGEMENTS}

This research was supported by grants from the Spanish Government (CGL2006-04025/BOS and Consolider-Ingenio Montes CSD2008-00040) and the Catalan Government (SGR 2009-458).

\section{REFERENCES}

[1] Numbers, R.L. The Creationists, Expanded Edition; Harvard University Press: Cambridge 2006.

[2] Peñuelas, J. Biosphere, Evolution, Brains and Sex. Vantage Press: New York, 1992.

[3] Margalef, R. Our Biosphere. Ecology Institute D-21385 Oldendorf/Luhe 997.

[4] Terradas, J. Una Biografía del Mundo. Destino: Barcelona 2006.

[5] Dyson, F. Origins of Life. Cambridge University Press: Cambridge 1999.
[6] Hunding, A.; Kepes, A.; Lancet, D.; Minsky, A.; Norris, V.; Raine, D.; Sriram, K.; Root-Bernstein, R. Compositional complementarity and prebiotic ecology in the origin of life. BioEssays, 2006, 28 , 399-412.

[7] Eigen, M.; Schuster, P. The Hypercycle. Springer Verlag: Berlin, Germany 1979.

[8] Maynard-Smith, J. Hypercycles and the origin of life. Nature, 1979, 280, 445.

[9] Fraser C.; Alm E.J.; Polz M.F.; Spratt B.G.; Hanage W.P. The bacterial species challenge: making sense of genetic and ecological diversity. Science, 2009, 323, 741-6.

[10] Syvanen, M. Cross-species gene transfer; implications for a new theory of evolution" J. Theor. Biol., 1985, 112, 333-343.

[11] Margulis, L. Symbiotic Planet (A New View of Evolution). Basic Books: Amherst MA 1998.

[12] Yoon, H.; Hackett, J.; Bhattacharya, D. A genomic and phylogenetic perspective on endosymbiosis and algal origin. J. Appl. Phycol., 2006, 18, 475-481.

[13] Falkowski, P.G.; Katz, -M.E.; Knoll, A.H.; Quigg, A.; Raven, J.A.; Schofield, O.; Taylor F. J. R. The evolution of modern eukaryotic phytoplankton. Science, 2004, 305(5682), 354-360.

[14] van Driel R.; Fransz P.F.; Verschure P.J. The eukaryotic genome: a system regulated at different hierarchical levels. J. Cell Sci., 2003, $116,4067-4075$.

[15] Medina, M. Genes and proteins form complex networks that constrict patterns of evolution. Proc. Natl. Acad. Sci. USA, 2005, 102, 6630-5.

[16] Jablonka, E.; Lamb, M.J. Evolution in Four Dimensions: Genetic, Epigenetic, Behavioral, and Symbolic Variation in the History of Life. MIT Press: Cambridge 2005.

[17] Moran, N.A. Symbiosis. Curr. Biol., 2006, 16, R866-R871.

[18] Hotopp, J.C.; Clark, M.E.; Oliveria, P.C. Widespread lateral gene transfer from intracellular bacteria to multicellular eukaryotes. Science, 2007, 317. (5845), 1753 - 1756.

[19] Imaizumi-Anraku, H.; Takeda, N.; Charpentier, M.; Perry, J.; Miwa, H.; Umehara, Y.; Kouchi, H.; Murakami, Y.; Mulder, L.; Vickers, K.; Pike, J.; Downie, J.A.; Wang, T.; Sato, S.; Asamizu, E.; Tabata, S.; Yoshikawa, M.; Murooka, Y.; Wu, G.J.; Kawasaki, S.; Parniske, M.; Hayashi, M. Plastid proteins crucial for symbiotic fungal and bacterial entry into plants and roots. Nature, 2005, 433, 527-531.

[20] Scott, J.J.; Dong-Chan Oh; Cetin Yuceer, M.; Klepzig, K.D; Clardy, J.; Currie, C.R. Bacterial protection of beetle-fungus mutualism. Science, 2008, 322, 63.

[21] Moran, N.A.; Degnan, P.H.S.; Santos, R.; Dunbar, E.; Ochman, H. The players in a mutualistic symbiosis: Insects, bacteria, viruses, and virulence genes. Proc. Natl. Acad. Sci. USA, 2005, 102(47), 16919-16926.

[22] Levinton, J.S. Genetics, paleontology and macroevolution. 2nd ed. Cambridge Univ. Press: Cambridge 2001.

[23] Jablonski, D. Biotic interactions and macroevolution: extensions missmatches across scales and levels. Evolution, 2008, 55, 715739.

[24] Reznick,D.N.; Ricklefs, R.E. Darwin's bridge between microevolution and macroevolution. Nature, 2009, 457, 837-842.

[25] Pal, C.; Macia, M.D.; Oliver, A.; Schachar, I.; Buckling, A. Coevolution with virus drives the evolution of bacterial mutation rates. Nature, 2007, 450, 1079-1081.

[26] Odling-Smee, F.; Laland, K.; Feldman, M. Niche construction: the neglected process in evolution. Princeton University Press: Princeton, NJ 2003

[27] Solé, R. V.; Bascompte, J. Self-organization in complex ecosystems. Princeton Univ. Press: Princeton, NJ 2006

[28] Ziman, J. Evolutionary models for technological change. In Ziman, J.; Ed. Technological innovation as an evolutionary process, Cambridge Univ. Press: Cambridge 2000.

[29] Allen, T. F. H.; Starr, T. B. Hierarchy: perspectives for ecological complexity. University of Chicago Press: Chicago 1982.

[30] Lewin, R. Life at the edge of chaos. University of Chicago Press: Oxford Chicago 1999.

[31] Kauffman, S. At home in the Universe, Oxford University Press 1996.

[32] Margalef, R. Mode of evolution of species in relation to their places in ecological succession. Proceedings of XVth International Congress of Zoology. 1959, pp. 787-789. 
[33] Ulfstrand, S. Savannah Lives: Animal Life and the Human Evolution of Africa. Oxford University Press: Oxford, 2003.

[34] Hawks, J.; Hunley K.; Sang-Hee, L.; Wolpoff, M. Population Bottlenecks and Pleistocene Human evolution. Mol. Biol. Evol., 2000, $17,2-2$.

[35] Wilson, E.O.; Hölldobler, B. The superorganism. Norton: New York 2008.

[36] Wilson, D.S.; Wilson, E.O. Evolution 'for the Good of the Group". Am. Sci., 2008, 96, 380.

[37] Keller, L. Levels of Selection in Evolution. Princeton University Press: Princeton, NJ 1999.

[38] Fehr, E.; Fischbacher. U. The nature of human altruism. Nature, 2003, 425, 785-91.
[39] Rindos, D. The Origins of Agriculture: An Evolutionary Perspective. Academic Press, New York 1984

[40] Diamond, J. Guns, Germs and Steel. W.W: Norton \& Co: New York 1996.

[41] Boserup, E. The Conditions of Agricultural Growth: The economics of agrarian change under population pressure. George Allen and Unwin: London 1965

[42] Hayden, E.C. The other strand. Nature, 2009, 457/12, 776-779.

[43] Hawks, J.; Wang, E.T.; Cochran, G.M.; Harpending ', H.C.; Moyzis, R.K. Recent acceleration of human adaptive evolution. Proc. Natl. Acad. Sci. USA, 2007, 104, 20753-20758.

(C) Terradas and Peñuelas; Licensee Bentham Open.

This is an open access article licensed under the terms of the Creative Commons Attribution Non-Commercial License (http://creativecommons.org/licenses/by-nc/3.0/) which permits unrestricted, non-commercial use, distribution and reproduction in any medium, provided the work is properly cited. 